\title{
Renal Development and Blood Pressure in Offspring from Dams Submitted to High-Sodium Intake during Pregnancy and Lactation
}

\author{
Terezila M. Coimbra, ${ }^{1}$ Heloísa D. C. Francescato, ${ }^{1}$ Ana Paula C. Balbi, ${ }^{1}$ \\ Evelyn C. S. Marin, ${ }^{1}$ and Roberto S. Costa ${ }^{2}$ \\ ${ }^{1}$ Department of Physiology, Faculty of Medicine, University of Sao Paulo, Avenida dos Bandeirantes 3900, \\ 14049-900, Ribeirao Preto, SP, Brazil \\ ${ }^{2}$ Department of Pathology, Faculty of Medicine, University of Sao Paulo, Avenida dos Bandeirantes 3900, \\ 14049-900, Ribeirao Preto, SP, Brazil
}

Correspondence should be addressed to Terezila M. Coimbra, tmcoimbr@fmrp.usp.br

Received 26 March 2012; Accepted 8 June 2012

Academic Editor: Frida Zaladek Gil

Copyright (C) 2012 Terezila M. Coimbra et al. This is an open access article distributed under the Creative Commons Attribution License, which permits unrestricted use, distribution, and reproduction in any medium, provided the original work is properly cited.

\begin{abstract}
Exposure to an adverse environment in utero appears to programme physiology and metabolism permanently, with long-term consequences for health of the fetus or offspring. It was observed that the offspring from dams submitted to high-sodium intake during pregnancy present disturbances in renal development and in blood pressure. These alterations were associated with lower plasma levels of angiotensin II (AII) and changes in renal AII receptor I $\left(\mathrm{AT}_{1}\right)$ and mitogen-activated protein kinase (MAPK) expressions during post natal kidney development. Clinical and experimental evidence show that the renin-angiotensin system (RAS) participates in renal development. Many effects of AII are mediated through MAPK pathways. Extracellular signalregulated protein kinases (ERKs) play a pivotal role in cellular proliferation and differentiation. In conclusion, high-sodium intake during pregnancy and lactation can provoke disturbances in renal development in offspring leading to functional and structural alterations that persist in adult life. These changes can be related at least in part with the decrease in RAS activity considering that this system has an important role in renal development.
\end{abstract}

\section{Introduction}

The risk of hypertension, renal, and cardiovascular disease are in part determined before birth by intrauterine factors. Exposure to an adverse environment in utero appears to programme physiology and metabolism permanently, with long-term consequences for health of the fetus or offspring $[1,2]$. The nephrogenesis in rats begins on embryonic day 12 and is completed at between 10 and 15 days after birth $[3,4]$. Clinical and experimental evidence show that the reninangiotensinn system (RAS) participates in renal development [5-11]. In the rat kidney, angiotensinogen expression is higher during the late gestation and newborn period whilst renin mRNA is detected from embryonic day 17 and is higher on embryonic day 20 and in newborns compared to adults
$[7,8]$. Renal AII content is several fold higher in newborn rats and mice than in their adult counterparts. The AII receptors are also expressed to a greater degree in newborn rats [9]. The mRNA for the type 1 AII receptor $\left(\mathrm{AT}_{1}\right)$ has been detected in the renal glomeruli of newborn rats during cellular proliferation and differentiation [10].

Increase in fibronectin, $\alpha$-SM-actin $(\alpha$-smooth muscle actin), PCNA (proliferating cell nuclear antigen) and p-ERK (extracellular signal-regulated protein kinase) expressions were observed in the renal cortex of 1- and 7-day-old rats, followed by a decrease during renal development [12]. The activation of these proteins may be at least in part due to an increase in renal AII and MAPKs contents in renal cortex. Fibronectin is one of the most important components of the extracellular matrix (ECM). Formation of the ECM 


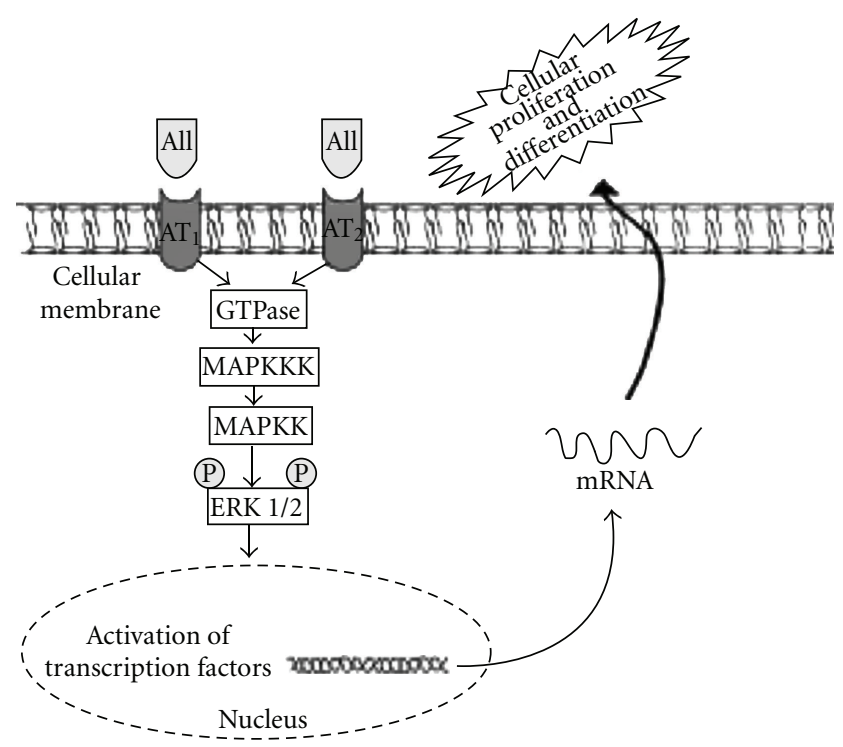

FIGURE 1: Schematic representation of angiotensin II (AII)-induced extracellular signal-regulated protein kinase (ERK) activation. AII acts through the type $1 \mathrm{AII}\left(\mathrm{AT}_{1}\right)$ and type $2 \mathrm{AII}\left(\mathrm{AT}_{2}\right)$ membrane receptors initiating intracellular signaling, with MAPK phosphorylation and activation of transcription factors in the nucleus, resulting in mRNA production for mediators of cellular differentiation and proliferation. GTPase: guanosine triphosphatase; MAPKKK: MAPKK kinase; MAPKK: MAPK kinase; ERK: extracellular signalregulated protein kinase.

represents a key event in kidney cell differentiation $[13,14]$. Fibronectin is a glycoprotein that can interact with some proteins from cell or ECM, inducing changes in cellular migration and adhesion [14]. It has also already been shown that human fetal mesangial cells express $\alpha$-SM-actin [15, $16]$ and that during kidney development, a large-scale cell proliferation has been observed to occur [17].

Mutations in genes that encode components of the RAS are associated with autosomal recessive renal tubular dysgenesis [18]. Kidneys from fetus with tubular dysgenesis show lack of tubule differentiation, and marked thickening of arterial walls. These fetuses also present anuria, oligohydramnios, and skull ossification defects. The kidney of 3-week-old angiotensin-deficient mice showed pelvic dilation with atrophic papilla, medial hyperplasia of interlobular artery and afferent arterioles, glomerulus with axial mesangial expansion, decrease in glomerular area, patchy fibrosis, mononuclear infiltrate in the interstitium, and dilated tubules in the outer medulla with interstitial fibrosis around [19].

Many effects of AII are mediated through mitogenactivated protein kinase (MAPK) pathways [20-22]. The MAPK family is comprised of serine/threonine kinases, which are divided into three major subgroups: extracellular signal-regulated protein kinases (ERKs), c-Jun $\mathrm{N}$-terminal kinases (JNKs)/stress-activated protein kinases, and p38 [23]. ERKs play a pivotal role in cellular proliferation and differentiation (Figure 1). In contrast, p38 and JNK MAPKs have been implicated in growth inhibition and apoptosis
[22]. AII-converting enzyme modulates the expression of components of the MAPKs family in kidney from neonatal rats [21]. A decrease in glomeruli number was observed in 15-day-old embryos cultured for 48 and 120 hours with ERK or p38 inhibitors [23]. Choi et al. found that the treatment of newborn rats with enalapril for 7 days increases JNK 2 and p38 MAPKs expressions in the kidney, and that these increases were temporally associated with higher number of apoptotic cells [21].

Twenty-four-hour urine volume and liquid intake were higher in the pregnant females submitted to high-salt intake compared to the pregnant females from the control group. The body weight variation was also higher in the pregnant females from the experimental group compared to pregnant females from the control group [24]. Taken together, these results may reflect an increase of extracellular fluid volume in dams from the experimental group that can lead to a decrease of the RAS activity. The alteration in RAS activity can be also happening in the newborn rats. Since AII has an important role in kidney development, the lower AII levels in offspring in response to a high-salt intake of dams during gestation and lactation can provoke disturbances in renal function and structure in these animals.

\section{Renal Development in Offspring from Dams Submitted to High-Sodium Intake during Pregnancy}

Maternal high-sodium intake has been associated with kidney fetal development through its effects on plasma volume and on SRA system leading to changes in renal function and structure $[12,25,26]$. We observed, in previous studies, decrease in fibronectin, $\alpha$-SM-actin, PCNA, p-ERK MAPK (Figure 2), $\mathrm{AT}_{1}$, and AII expressions in the renal cortex of 1-day-old pups from dams subjected to sodium intake compared to same age control rats [12]. Therefore, there was a temporal association between the reduction of AII and p-ERK MAPK expressions and the decrease of $\alpha$ SM-actin, fibronectin, and PCNA expressions in renal cortex, suggesting a possible relationship between these findings. We also observed a decrease in the expression of $\mathrm{AT}_{1}$ receptors in 1-day-old rats born to mothers that received a highersalt intake compared with controls of same age. Since kidney development is influenced by the RAS, possible functional changes in the RAS may occur in offspring due to the lower AII levels in response to a high-salt intake of dams during pregnancy. Some effects of AII are mediated through pERK pathway [20-22]. ERKs play a pivotal role in cellular proliferation and differentiation (Figure 1). On the other hand, increase in p-p38 and p-JNK MAPKs expressions were observed in 30-day-old pups of dams fed high-sodium diet. JNKs and p-38 have been implicated in growth inhibition and apoptosis.

Our results show that mesangial cell and interstitial fibroblast activation occurs during kidney differentiation, as confirmed by the increased expression of fibronectin and PCNA in the renal cortex from 1- and 7-day-old animals. The activation of these cells may be due, at least in part, 

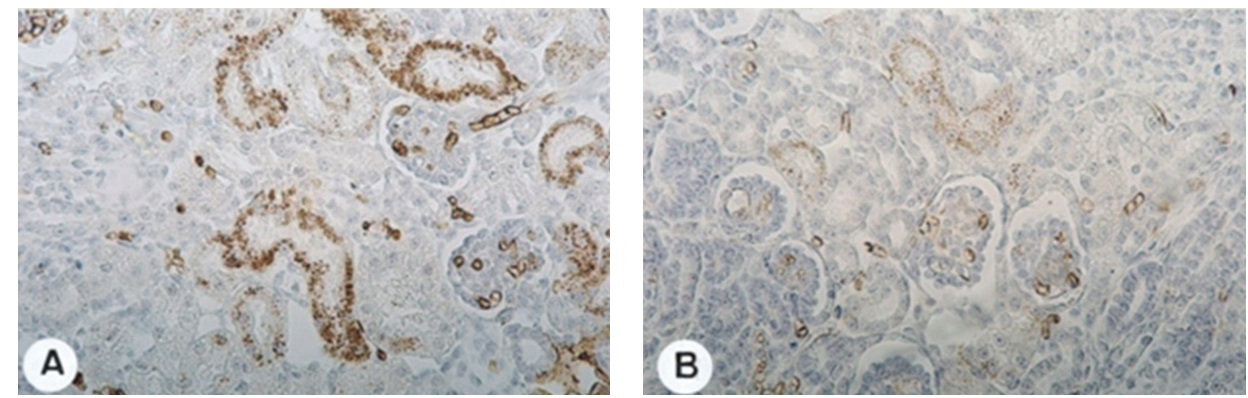

FIGURE 2: Immunolocalization of phospho-extracellular signal-regulated protein kinase (p-ERK) in renal cortex of offspring from dams submitted (B) or not (A) to high-sodium intake during pregnancy and lactation at 1 day of age (original magnification $280 \mathrm{x}$ ). Note that the reactions are more intense in $(\mathrm{A})$ than in $(\mathrm{B})$.
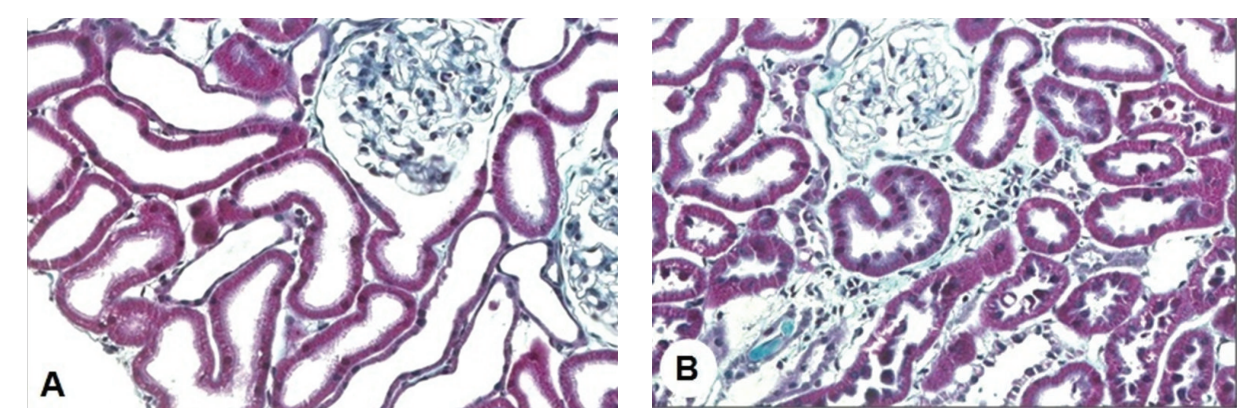

FIGURE 3: Masson's trichrome stained histological sections of renal cortex of rats from dams submitted to high-sodium intake (B) and of the same age control rats (A) at 120 days of age (original magnification 280x).

to an increase in the renal AII production. Rats born from mothers that received a high-salt intake presented at 1st day of age a decrease in $\alpha$-SM-actin, fibronectin, and PCNA expressions in the renal cortex, as well as a reduction in the number of AII-positive cells in glomerular and interstitial compartments compared with controls of the same age. There is some experimental evidence suggesting that AII can induce this phenotypic modification of these cells $[27,28]$. The upregulation of $\alpha$-SM-actin synthesis by these cells is frequently associated with increased cell proliferation and ECM. During kidney development, a large-scale proliferation has been observed [17]. Therefore, changes in the renal expression of AII in animals born from mothers fed high-salt diet might affect renal cell proliferation and ECM production during postnatal development. A decline in GFR was also observed in 30-day-old animals from this group. These data demonstrate that disturbances occurring during intrauterine life can induce persistent alterations in the biology of the pups in adult life.

Koleganova et al. [26] verified that maternal highsalt intake leads to reduced final number of glomeruli, glomerulomegaly, and albuminuria in the offspring. Cardoso et al. [25] found that prenatally and postnatally sodiumoverloaded rats showed increased proteinuria and reduced glomerular filtration rate (GFR) that were associated with kidney oxidative stress. Therefore, this damage in the offspring renal tissue may be related at least in part with disturbances in antioxidant defense in dams. Besides this it, was observed that the antioxidant defenses were altered in newborns [29]. Beauséjour et al. [30] showed that the marker of oxidative stress (nitrotyrosine expression), the producer of nitric oxide (nitric oxide synthases), and apoptotic index were increased in kidneys from pregnant rats that consumed a diet with high sodium which was associated with decrease of $\mathrm{Na}^{+}-\mathrm{K}^{+}$-ATPase mRNA and activity. In a study performed with the renal proximal tubular cells, it was found that nitric oxide-derived products (such as peroxynitrite) inhibited $\mathrm{Na}^{+}-\mathrm{K}^{+}$-ATPase activity via the oxidation of thiol groups of this enzyme [31]. Guzman et al. reported that this inhibition was accompanied by a reduction in $\mathrm{Na}^{+}$-dependent solute transport [32]. In addition, it was also observed that endogenous nitric oxide plays a direct inhibitory role in $\mathrm{Na}^{+}-\mathrm{K}^{+}$-ATPase activity in the kidney [33]. Koleganova et al. (2011) showed that the expression of $\alpha_{1}-\mathrm{Na}^{+}-\mathrm{K}^{+}$-ATPase protein and RNA levels at term was significantly lower in offspring of dams with high sodium diet [26].

We also found [24] higher scores for glomerulosclerosis and tubulointerstitial lesions in renal cortex of 120-day-old offspring from dams subjected to increase in saline intake compared to the same age control rats (Figure 3). These alterations were associated to an increase in the number of macrophages in renal cortex and glomeruli. Macrophages activated by hypoxia and the oxidative stress present in the injured tissue can release fibrogenic peptides, such as TGF$\beta$ (transforming growth factor $\beta$ ), interleukin-1, endothelin, 
AII, and radical oxygen species, contributing to intensify the inflammatory process and fibrosis [34].

\section{Blood Pressure in Offspring from Dams Submitted to High-Sodium Intake during Pregnancy}

Higher blood pressure was observed in newborns from dams submitted to high-sodium intake during pregnancy and lactation $[12,24,25,35]$. It was observed by da Silva et al. that adult rats submitted to prenatal salt overload presented RAS functional disturbances [36]. They found that plasma renin activity did not modify in response to high-salt intake in the adult rats submitted to a high-salt environment during the prenatal period. There is evidence that AII receptors in brain regions involved in cardiovascular control and water and electrolyte balance are influenced by perinatal high-sodium intake $[37,38]$. It was also shown that pressor response to peripheral AII is increased in adult rats submitted to perinatal salt ingestion compared to basal salt intake $[38,39]$. However, study from Porter et al. [40] showed that limiting maternal exposure to a high-sodium diet to the prenatal period is not sufficient to program lasting hypertension in offspring, but an enhanced pressor and tachycardic response to acute stress does persist in adulthood. Therefore, the authors concluded that repeated enhanced response to acute stress observed in these animals has the potential to produce permanent cardiovascular disease.

\section{Conclusion}

High-sodium intake during pregnancy and lactation can provoke disturbances in renal development in offspring leading to functional (proteinuria, decrease in GFR, and higher blood pressure) and structural alterations (lower glomeruli numbers, glomerulomegaly, glomerulosclerosis, and tubulointerstitial lesions) that persist in adult life. These changes can be related at least in part with RAS activity that has an important role in renal development.

\section{References}

[1] D. J. P. Barker, S. P. Bagby, and M. A. Hanson, "Mechanisms of disease: in utero programming in the pathogenesis of hypertension," Nature Clinical Practice Nephrology, vol. 2, no. 12, pp. 700-707, 2006.

[2] V. M. Vehaskari, D. H. Aviles, and J. Manning, "Prenatal programming of adult hypertension in the rat," Kidney International, vol. 59, no. 1, pp. 238-245, 2001.

[3] S. K. Nigam, A. C. Aperia, and B. M. Brenner, "Development and maturation of the kidney," in Dans: The Kidney: Physiology and Pathology, B. M. Brenner and F.C. Rector, Eds., pp. 72-98, WB Saunders, Philadelphia, Pa, USA, 5th edition, 1996.

[4] W. Reeves, J. P. Caulfield, and M. G. Farquhar, "Differentiation of epithelial foot processes and filtration slits. Sequential appearance of occluding junctions, epithelial polyanion, and slit membranes in developing glomeruli," Laboratory Investigation, vol. 39, no. 2, pp. 90-100, 1978.
[5] A. S. Woolf and P. J. D. Winyard, "Advances in the cell biology and genetics of human kidney malformations," Journal of the American Society of Nephrology, vol. 9, no. 6, pp. 1114-1125, 1998.

[6] I. V. Yosypiv, M. Schroeder, and S. S. El-Dahr, "Angiotensin II type 1 receptor-EGF receptor cross-talk regulates ureteric bud branching morphogenesis," Journal of the American Society of Nephrology, vol. 17, no. 4, pp. 1005-1014, 2006.

[7] R. A. Gomez, K. R. Lynch, B. C. Sturgill et al., "Distribution of renin mRNA and its protein in the developing kidney," American Journal of Physiology, vol. 257, no. 5, pp. F850-F858, 1989.

[8] R. A. Gomez, A. Tufro-McReddie, A. D. Everett, and E. S. Pentz, "Ontogeny of renin and AT1 receptor in the rat," Pediatric Nephrology, vol. 7, no. 5, pp. 635-638, 1993.

[9] M. A. Millan, P. Carvallo, S. Izumi, S. Zemei, K. J. Catt, and G. Aguilera, "Novel sites of expression of functional angiotensin II receptors in the late gestation fetus," Science, vol. 244, no. 4910, pp. 1340-1342, 1989.

[10] A. Tufro-McReddie, J. K. Harrison, A. D. Everett, and R. A. Gomez, "Ontogeny of type 1 angiotensin II receptor gene expression in the rat," Journal of Clinical Investigation, vol. 91, no. 2, pp. 530-537, 1993.

[11] E. F. Grady, L. A. Sechi, C. A. Griffin, M. Schambelan, and J. E. Kalinyak, "Expression of AT2 receptors in the developing rat fetus," Journal of Clinical Investigation, vol. 88, no. 3, pp. 921-933, 1991.

[12] A. P. C. Balbi, R. S. Costa, and T. M. Coimbra, "Postnatal renal development of rats from mothers that received increased sodium intake," Pediatric Nephrology, vol. 19, no. 11, pp. 12121218, 2004.

[13] A. B. Roberts, B. K. McCune, and M. B. Sporn, "TGF- $\beta$ : regulation of extracellular matrix," Kidney International, vol. 41, no. 3, pp. 557-559, 1992.

[14] J. P. Thiery, J. L. Duband, S. Dufour, P. Savagner, and B. A. Imhof, "Role of fibronectins in embryogenesis," in Dans: Biology of Extracellular Matrix: Fibronectin, D. F. Mosher, Ed., pp. 181-212, Academic Press, San Diego, Calif, USA, 1989.

[15] A. V. Carey, R. M. Carey, and R. A. Gomez, "Expression of $\alpha$ smooth muscle actin in the developing kidney vasculature," Hypertension, vol. 19, no. 2, supplement, pp. II168-II175, 1992.

[16] K. Naruse, M. Fujieda, E. Miyazaki et al., "An immunohistochemical study of developing glomeruli in human fetal kidneys," Kidney International, vol. 57, no. 5, pp. 1836-1846, 2000.

[17] S. Omori, M. Hida, K. Ishikura, S. Kuramochi, and M. Awazu, "Expression of mitogen-activated protein kinase family in rat renal development," Kidney International, vol. 58, no. 1, pp. 27-37, 2000.

[18] O. Gribouval, M. Gonzáles, T. Neuhaus et al., "Mutations in genes in the renin-angiotensin system are associated with autosomal recessive renal tubular dysgenesis," Nature Genetics, vol. 37, no. 9, pp. 964-968, 2005.

[19] F. Niimura, P. A. Labosky, J. Kakuchi et al., "Gene targeting in mice reveals a requirement for angiotensin in the development and maintenance of kidney morphology and growth factor regulation," Journal of Clinical Investigation, vol. 96, no. 6, pp. 2947-2954, 1995.

[20] T. Kubo, T. Ibusuki, S. Chiba, T. Kambe, and R. Fukumori, "Mitogen-activated protein kinase activity regulation role of angiotensin and endothelin systems in vascular smooth muscle cells," European Journal of Pharmacology, vol. 411, no. 1-2, pp. 27-34, 2001. 
[21] B. M. Choi, K. H. Yoo, I. S. Bae et al., "Angiotensinconverting enzyme inhibition modulates mitogen-activated protein kinase family expressions in the neonatal rat kidney," Pediatric Research, vol. 57, no. 1, pp. 115-123, 2005.

[22] D. Kumar, V. Menon, W. R. Ford, A. S. Clanachan, and B. I. Jugdutt, "Effect of angiotensin II type 2 receptor blockade on mitogen activated protein kinase during myocardial ischemiareperfusion," Molecular and Cellular Biochemistry, vol. 258, no. 1-2, pp. 211-218, 2004.

[23] M. Hida, S. Omori, and M. Awazu, "ERK and p38 MAP kinase are required for rat renal development," Kidney International, vol. 61, no. 4, pp. 1252-1262, 2002.

[24] E. C. S. Marin, A. P. C. Balbi, H. D. C. Francescato, C. G. Alves Da Silva, R. S. Costa, and T. M. Coimbra, "Renal structure and function evaluation of rats from dams that received increased sodium intake during pregnancy and lactation submitted or not to 5/6 nephrectomy," Renal Failure, vol. 30, no. 5, pp. 547$555,2008$.

[25] H. D. Cardoso, E. V. Cabral, L. D. Vieira-Filho, A. Vieyra, and A. D. O. Paixão, "Fetal development and renal function in adult rats prenatally subjected to sodium overload," Pediatric Nephrology, vol. 24, no. 10, pp. 1959-1965, 2009.

[26] N. Koleganova, G. Piecha, E. Ritz et al., "Both high and low maternal salt intake in pregnancy alter kidney development in the off spring," American Journal of Physiology, vol. 301, no. 2, pp. F344-F354, 2011.

[27] R. J. Johnson, C. E. Alpers, A. Yoshimura et al., "Renal injury from angiotensin II-mediated hypertension," Hypertension, vol. 19, no. 5, pp. 464-474, 1992.

[28] Y. Chen, D. Lasaitiene, B. G. Gabrielsson et al., "Neonatal losartan treatment suppresses renal expression of molecules involved in cell-cell and cell-matrix interactions," Journal of the American Society of Nephrology, vol. 15, no. 5, pp. 1232-1243, 2004.

[29] R. P. Jankov, A. Negus, and A. K. Tanswell, "Antioxidants as therapy in the newborn: some words of caution," Pediatric Research, vol. 50, no. 6, pp. 681-687, 2001.

[30] A. Beauséjour, V. Houde, K. Bibeau, R. Gaudet, J. St-Louis, and M. Brochu, "Renal and cardiac oxidative/nitrosative stress in salt-loaded pregnant rat," American Journal of Physiology, vol. 293, no. 4, pp. R1657-R1665, 2007.

[31] C. Zhang, S. Z. Imam, S. F. Ali, and P. R. Mayeux, "Peroxynitrite and the regulation of $\mathrm{Na}^{+}, \mathrm{K}^{+}$-ATPase activity by angiotensin II in the rat proximal tubule," Nitric Oxide, vol. 7, no. 1, pp. 30-35, 2002.

[32] N. J. Guzman, M. Z. Fang, S. S. Tang, J. R. Ingelfinger, and L. C. Garg, "Autocrine inhibition of $\mathrm{Na}^{+} / \mathrm{K}^{+}$-ATPase by nitric oxide in mouse proximal tubule epithelial cells," Journal of Clinical Investigation, vol. 95, no. 5, pp. 2083-2088, 1995.

[33] D. G. Kang, J. W. Kim, and J. Lee, "Effects of nitric oxide synthesis inhibition on the Na,K-ATPase activity in the kidney," Pharmacological Research, vol. 41, no. 1, pp. 123-127, 2000.

[34] K. S. Eardley and P. Cockwell, "Macrophages and progressive tubulointerstitial disease," Kidney International, vol. 68, no. 2, pp. 437-455, 2005.

[35] N. Hazon, C. Parker, R. Leonard, and I. W. Henderson, "Influence of an enriched dietary sodium chloride regime during gestation and suckling and post-natally on the ontogeny of hypertension in the rat," Journal of Hypertension, vol. 6, no. 7, pp. 517-524, 1988.

[36] A. A. da Silva, I. L. de Noronha, I. B. de Oliveira, D. M. C. Malheiros, and J. C. Heimann, "Renin-angiotensin system function and blood pressure in adult rats after perinatal salt overload," Nutrition, Metabolism and Cardiovascular Diseases, vol. 13, no. 3, pp. 133-139, 2003.

[37] K. E. Moe, "The salt intake of rat dams influences the salt intake and brain angiotensin receptors of their adult offspring," Society of Neuroscience Abstract, vol. 13, Article ID 1169A, 1987.

[38] R. J. Contreras, D. L. Wong, R. Henderson, K. S. Curtis, and J. C. Smith, "High dietary $\mathrm{NaCl}$ early in development enhances mean arterial pressure of adult rats," Physiology and Behavior, vol. 71, no. 1-2, pp. 173-181, 2000.

[39] R. J. Contreras, "Differences in perinatal $\mathrm{NaCl}$ exposure alters blood pressure levels of adult rats," American Journal of Physiology, vol. 256, no. 1, pp. R70-R77, 1989.

[40] J. P. Porter, S. H. King, and A. D. Honeycutt, "Prenatal highsalt diet in the Sprague-Dawley rat programs blood pressure and heart rate hyperresponsiveness to stress in adult female offspring," American Journal of Physiology, vol. 293, no. 1, pp. R334-R342, 2007. 


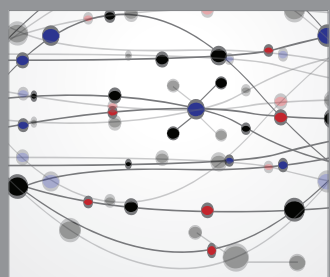

The Scientific World Journal
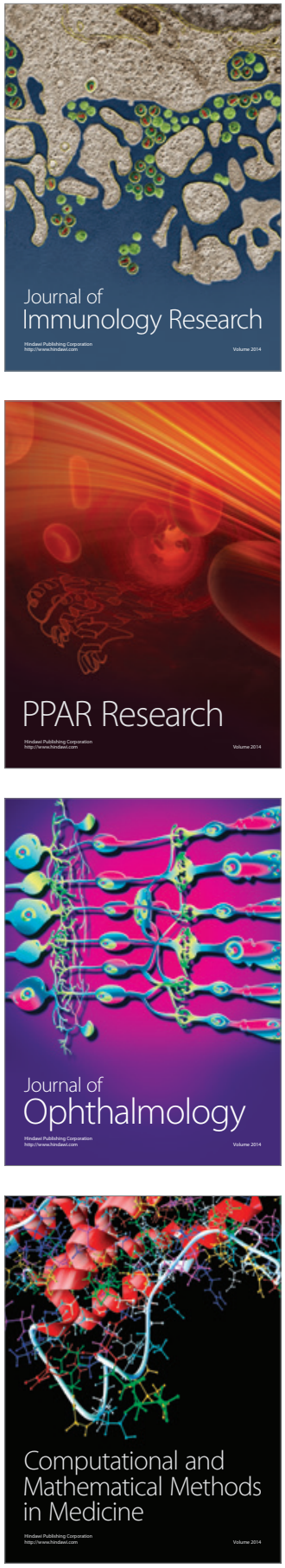

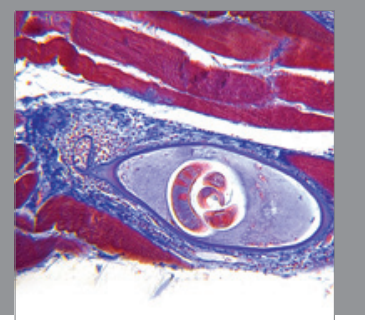

Gastroenterology

Research and Practice
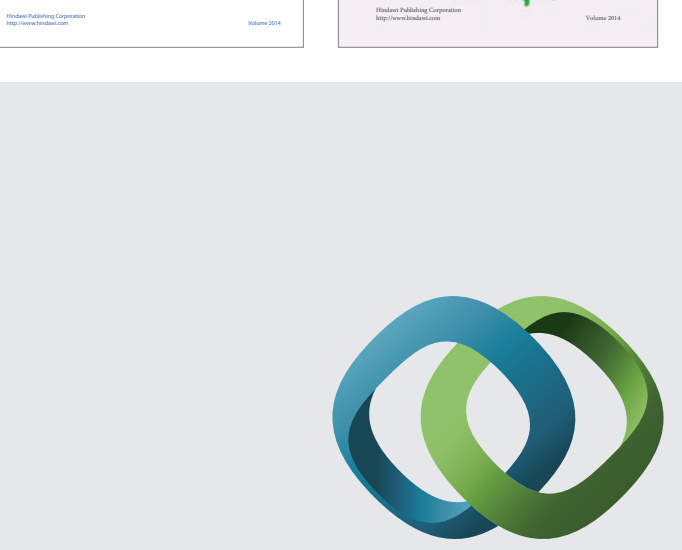

\section{Hindawi}

Submit your manuscripts at

http://www.hindawi.com
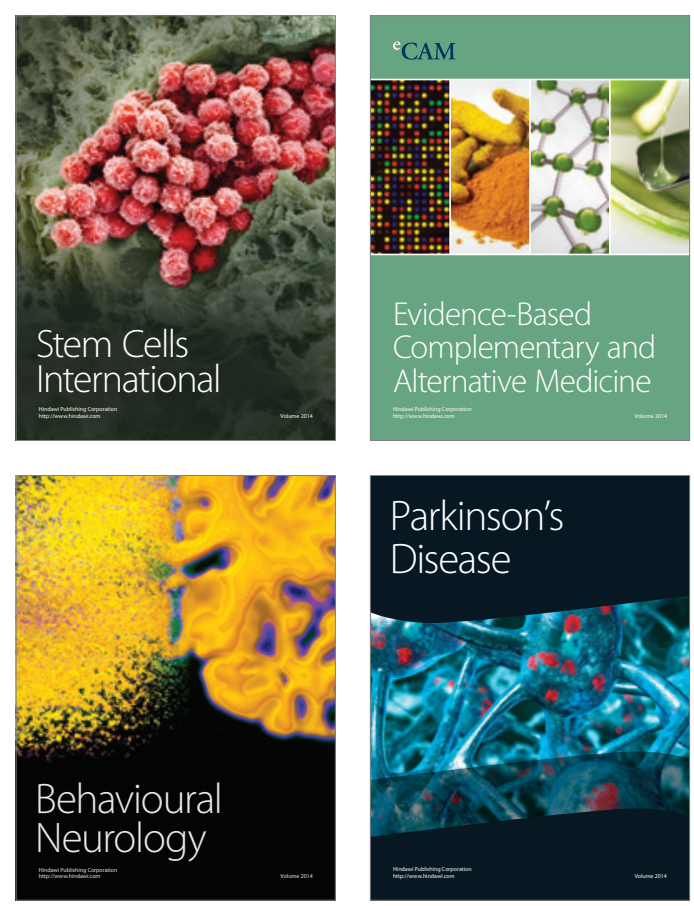

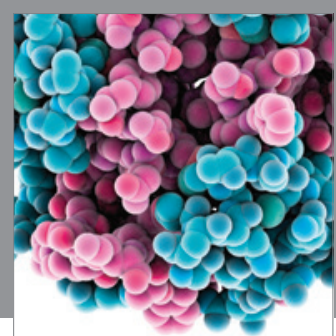

Journal of
Diabetes Research

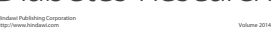

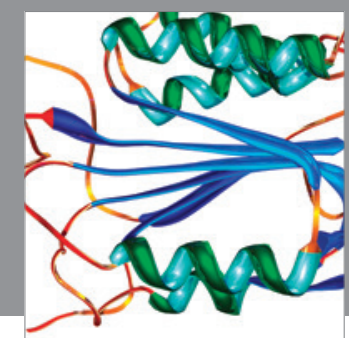

Disease Markers
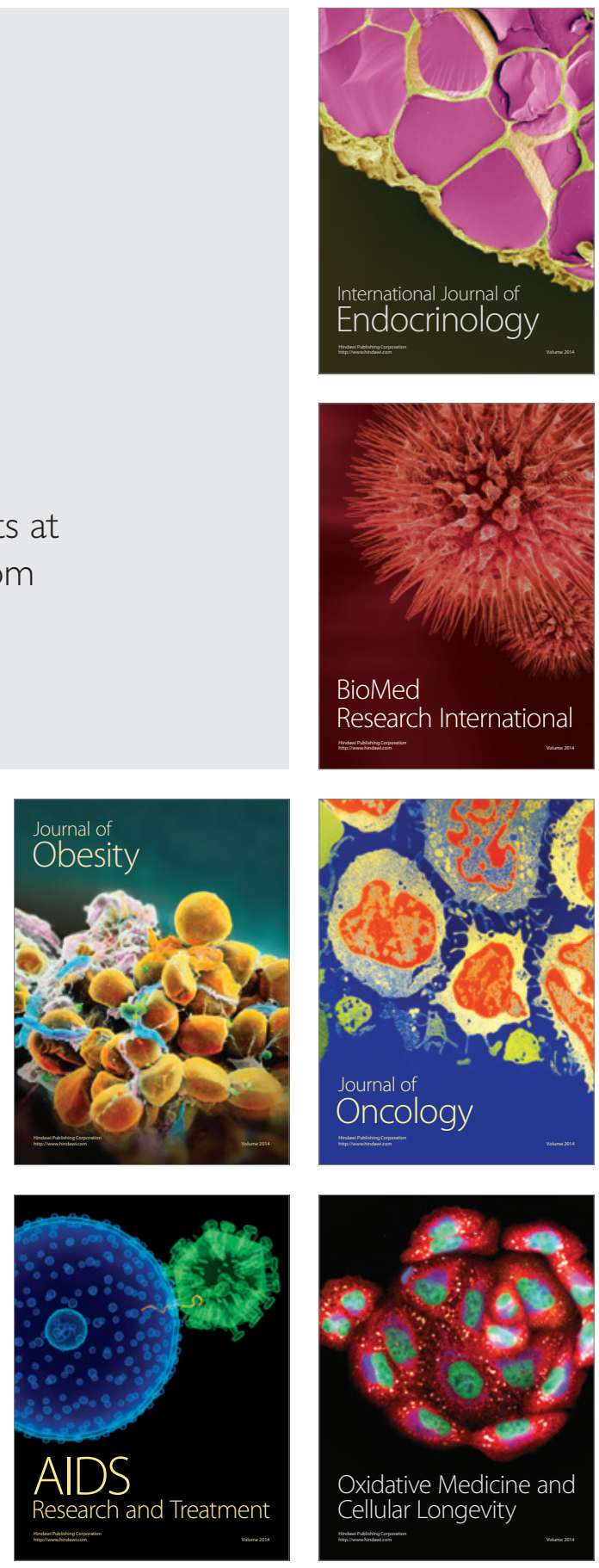